\title{
STRESS-STRAIN RELATIONSHIPS OF CLAYS BASED ON THE MOBILIZED PLANE
}

\author{
Hajime Matsuora*
}

\begin{abstract}
Taking special notice of the similarity of shear characteristics between sands and clays, the author sought to apply to clays the stress-strain relationships which were derived from the microscopic analysis and which were experimentally verified with reference to sands and other granular materials. The stress-strain relationships were verified with respect to measured data of drained triaxial compression tests on various kinds of normally consolidated and overconsolidated clays and the related microscopic mechanism was also considered. It was shown from the test results that the shear phenomena of sands and clays could be analyzed on the basis of the same principle, suggesting that they might occur in a fundamentally similar mechanism.
\end{abstract}

Key words: clay, dilatancy, drained shear, microscopy, overconsolidation, soil structure, stress-strain curve, triaxial compression test

IGC: $\quad$ D6/D3

\section{INTRODUCTION}

It is the generally accepted theory in soil mechanics that sands and clays are essentially different materials and, therefore, should be studied for their mechanical properties separately from each other. In fact, when one takes into account not merely the difference in grain size ( 4.76 to $0.074 \mathrm{~mm}$ for sand and less than $0.005 \mathrm{~mm}$ for clay) but also the properties of adsorbed water surrounding clay particles, the physicochemical interaction between clays particle and pore fluid, the variety of structures formed by clay particles and so on, one naturally reaches the conclusion that the mechanical properties of sands and those of clays are different. For example, the time effects such as outstanding creep characteristics and stress relaxation characteristics and temperature effects manifested by clays are thought to have something to do with the aforementioned properties. The author focuses his particular attention to the observation that sands and clays exhibit similarity in shear behaviors, applies to clays the various formulas of stress-strain relationships derived in the previous papers (Matsuoka, 1973 ; 1974) with respect to sands and, at the same time, considers the related mechanism.

\section{SPECIMENS AND APPARATUS USED IN TESTS}

The Fujinomori clay, the Umeda clay and a Kaoline clay were used as test specimens. The Fujinomori clay is collected in the vicinity of Fujinomori, Fushimi of Kyoto and is sold in the form of dry powdered clay. For the test, this clay was kneaded with water and then subjected to preliminary consolidation (under a pressure of about $0.5 \mathrm{~kg} / \mathrm{cm}^{2}$ ) prior

* Assistant Professor, Disaster Prevention Research Institute, Kyoto University, Gokasho, Uji, Kyoto. Written discussions on this paper should be submitted before April 1, 1975. 
to use. The liquid limit, plastic limit, and specific gravity of the clay are $44 \%, 26 \%$, and 2.68 , respectively. In the triangular classification chart, it fell in the category of silty clay loam.

The Umeda clay was a remolded, reconsolidated clay prepared from the alluvial clay from Umeda, Osaka. The liquid limit, plastic limit, and specific gravity of the clay are $77 \%$, $32 \%$, and 2.68 , respectively. In the triangular classification chart, it fell in the category of clay.

The Kaoline clay was prepared by mixing kaoline and bentonite at a ratio of $40: 1$ (by weight). The mixture was kneaded with water and then subjected to preliminary consolidation under a pressure of about $2 \mathrm{~kg} / \mathrm{cm}^{2}$. The liquid limit, plastic limit, and specific gravity of the clay are $50 \%, 33 \%$, and 2.72 , respectively.

Test specimens were formed in the shape of cylinders $3.5 \mathrm{~cm}$ in diameter and $8 \mathrm{~cm}$ in height. To lessen possible friction on the upper and lower end faces, rubber membranes coated with silicone grease were inserted between the loading cap and the upper end of the test specimen, and between the lower end of the test specimen and an Araldite disc mounted on a porous stone. To provide drainage, not only the lateral face of the test specimen but also that of the porous stone were wrapped in filter paper.

For the present test an ordinary triaxial apparatus (N.G.I. type made by Geonor) was used. In the drained triaxial tests, the shear speed was fixed at a sufficiently low level of $7200.01 \mathrm{~min} / 10 \mathrm{~mm}$.

\section{VERIFICATION BY TEST DATA}

Verification of Relationship between Shear-Effective Normal Stress Ratio $\left(\tau / \sigma_{N}\right)$ and NormalShear Strain Increment Ratio $\left(d \varepsilon_{N} / d \gamma\right)$

The formula of the $\tau / \sigma_{N} \sim d \varepsilon_{N} / d \gamma$ relationship on the mobilized plane derived in the previous papers (Murayama and Matsuoka, 1971 ; Matsuoka, 1972 ; Murayama and Matsuoka, 1973 ; Matsuoka, 1974) is restated below :

$$
\frac{\tau}{\sigma_{N}}=\lambda \cdot\left(-\frac{d \varepsilon_{N}}{d \gamma}\right)+\mu
$$

where, $\mu$ denotes the coefficient of interparticle friction and $\lambda$ a constant on the order of 1.1 to 1.5 to be determined by the value of $\mu$. Here, Eq. (1) will be discussed with reference to the data of the drained triaxial test on clays. To begin with, Fig. 1 represents the data of the drained triaxial compression test conducted by Ladanyi et al. (1965) on

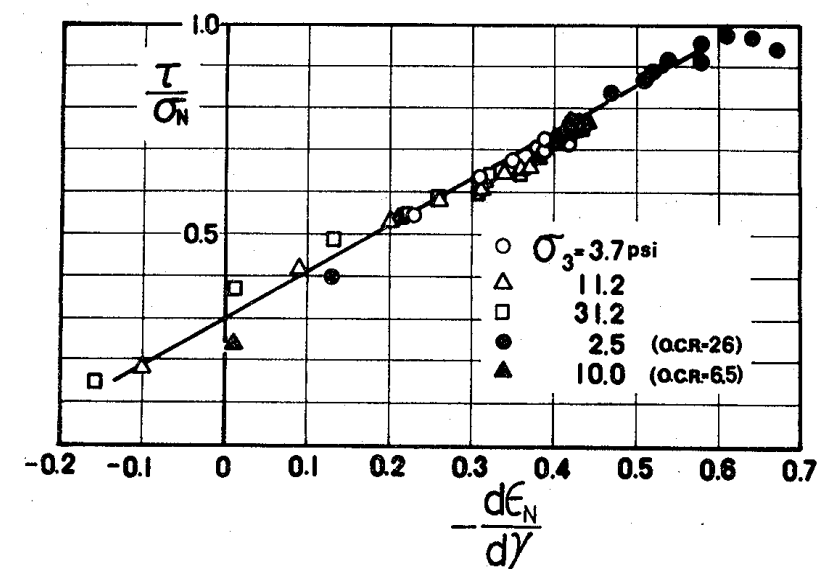

Fig. 1. Relationship between $\tau / \sigma_{N}$ and $d \varepsilon_{N} / d \gamma$ on one mobilized plane measured in drained triaxial compression test on normally consolidated and overconsolidated clays a clay, as rearranged in terms of the $\tau / \sigma_{N}$ $\sim d \varepsilon_{N} / d \gamma$ relationship on a single mobilized plane. The plots are seen to form a substantially straight line and found to give $\mu=0.30$ and $\lambda=1.1$. What is particularly interesting to note is the fact that the plots substantially fall on the same line for both normal consolidation (N.C. ; indicated by open marks) and overconsolidation (O.C. ; indicated by solid marks). The data of the drained triaxial test on a clay by Henkel (1956) and the data of the drained triaxial test on a silt by Penman (1953) when arranged in the method mentioned above, seem to give substantially linear plots (relevant data 
omitted here). The value of the ordinate intercept appears to vary in an approximate range from 0.2 to 0.4 , depending on the kind of clays. It is considered to be equivalent to the physical constant corresponding to the interparticle friction of sands.

Strictly speaking, the shear test aimed at verification of Eq. (1) ought to be performed under a constant mean effective principal stress $\sigma_{m}$ which is considered to produce strain exclusively ascribable to dilatancy. Throughout this paper, the stress $\sigma$ is used to mean the effective stress invariably, although it is not expressed as $\sigma^{\prime}$. Fig. 2 represents the results of the drained triaxial test (N.C., initial water content $w_{i}=33.2 \%$ ) on the Fujinomori clay with the mean principal stress $\sigma_{m}$ fixed at $1.0 \mathrm{~kg} / \mathrm{cm}^{2}$, rearranged in terms of the $\tau / \sigma_{N} \sim d \varepsilon_{N} / d \gamma$ relationship on the mobilized plane. From this diagram, it is seen that in the initial stage of shear, the plots tend to go up from below because of insufficient mobilization of $\phi_{\mu}$, that in the subsequent stage, the plots describe a substantially straight line and that the linear gradient $\lambda$ is approximately 1.1 and the ordinate intercept $\mu$ seems to assume a value on the order of 0.30 . Fig. 3 represents the results of the drained triaxial test $\left(w_{i}=30.7 \%\right)$ using an overconsolidated specimen of the Fujinomori clay (O.C.R.=1.5) and involving a fixed mean principal stress $\sigma_{m}=1.0 \mathrm{~kg} / \mathrm{cm}^{2}$, as rearranged in terms of the relationship mentioned above. The ordinate intercept is in the neighborhood of 0.27 . Comparison of this diagram with that of Fig. 2 leads to a speculation that the data give substantially the same linear plots as those of the normally consolidated clay.

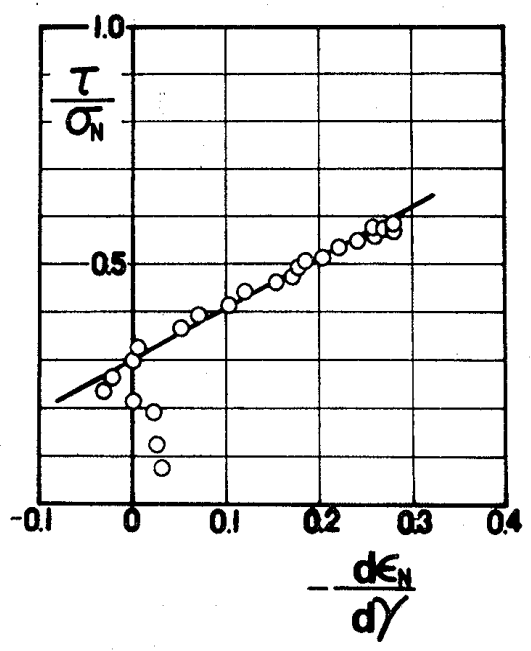

Fig. 2. Relationship between $\tau / \sigma_{N}$ and $d \varepsilon_{N} / d \gamma$ on one mobilized plane measured in drained triaxial compression test on normally consolidated Fujinomori clay

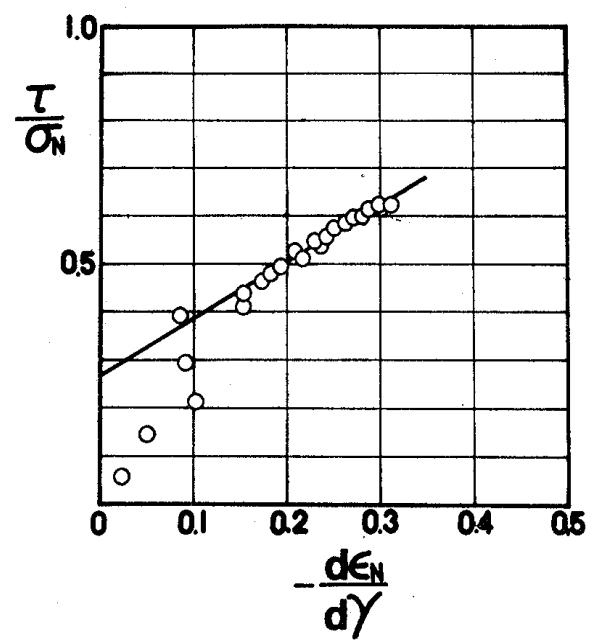

Fig. 3. Relationship between $\tau / \sigma_{N}$ and $d \varepsilon_{N} / d \gamma$ on one mobilized plane measured in drained triaxial compression test on overconsolidated Fujinomori clay

Fig. 4 represents the results of the drained triaxial test using the Umeda clay of normal consolidation under a fixed value of $\sigma_{3}=1.0 \mathrm{~kg} / \mathrm{cm}^{2}$, as rearranged in terms of the same relationship. From this diagram, the values of $\lambda$ and $\mu$ are found to be 0.9 and 0.42 , respectively. Fig. 5 represents the results of the drained triaxial test on the Kaoline clay (O.C.R. $=1.5)$ under a fixed value $\sigma_{3}=4.0 \mathrm{~kg} / \mathrm{cm}^{2}$. The values of $\lambda$ and $\mu$ are found from this diagram to be 1.2 and 0.29 , respectively.

Now, the author proposes to consider the problem of why Eq. (1) derived with respect to such granular soils as sands is likewise applicable to clays. Fig. 6 represents the structure of a quick clay which Pusch (1970) has sketched from many electron microscopic observations of the structure of clay. Pusch holds a position that, in clay, masses each composed of an assembly of several clay particles called aggregates are present in the form of secon- 


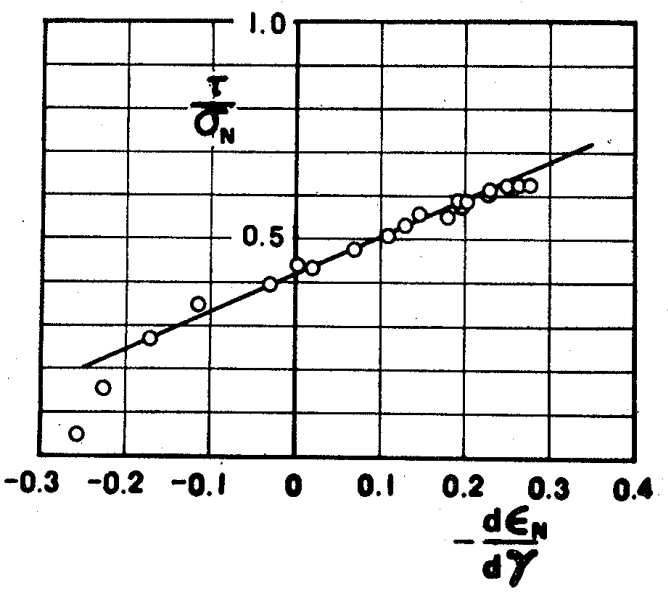

Fig. 4. Relationship between $\tau / \sigma_{N}$ and $d \varepsilon_{N} / d \gamma$ on one mobilized plane measured in drained triaxial compression test on normally consolidated Umeda clay

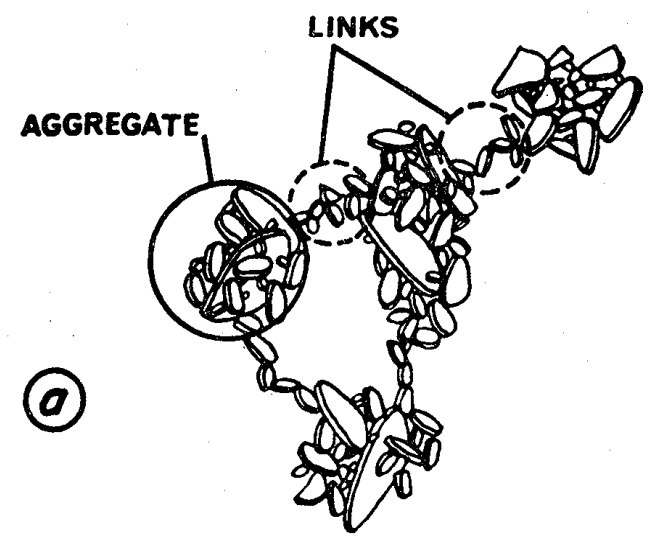

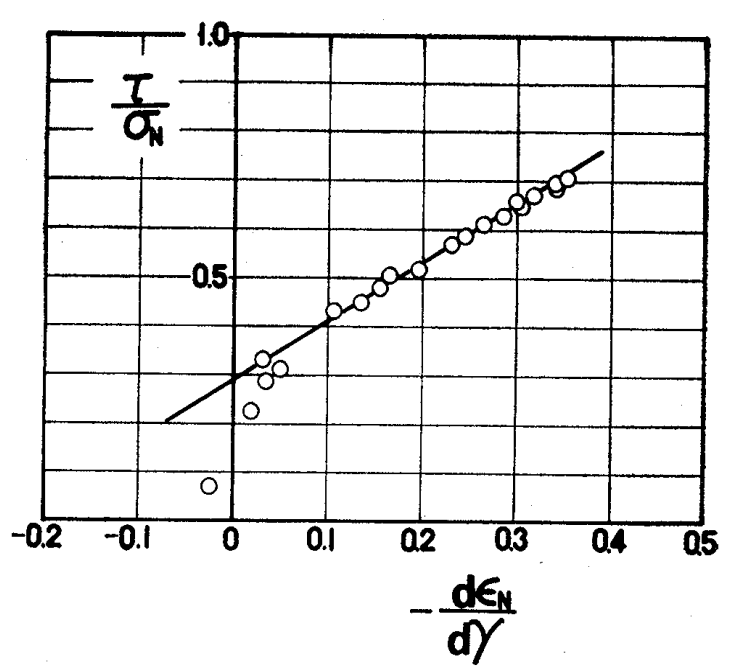

Fig. 5. Relationship between $\tau / \sigma_{N}$ and $d \varepsilon_{N} / d \gamma$ on one mobilized plane measured in drained triaxial compression test on overconsolidated Kaoline clay

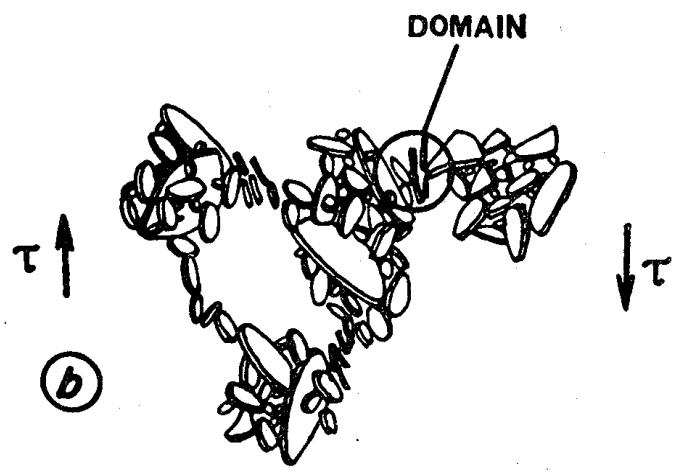

Fig. 6. Microstructure of a quick clay (after Pusch, 1970)

dary particles. If such aggregates behave as the unit of activity in shear similarly to the individual sand grains, then there may be a possibility that the shear mechanism with respect to sands will be applicable to clays. The question as to whether this is really the true mechanism of shear in clay is yet to be answered by effective use of the electron

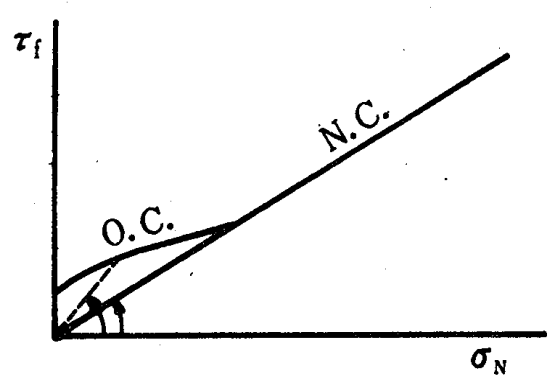

Fig. 7. Mohr's failure envelope of normally consolidated and overconsolidated clays microscope, $X$-ray diffraction system and other instruments (Matsuo and Kamon, 1973). For the purpose of the present study, the author wishes to proceed with analysis by assuming the aforementioned hypothesis as provisionally acceptable.

According to Eq. (1), one can easily postulate the phenomenon that Mohr's failure envelope as represented in Fig. 7 gives rise to two linear (or curved) lines of different inclinations depending on whether the soil is normally consolidated or overconsolidated. In most cases, the failure envelope of normally consolidated clays gives a substantially straight line past the origin. A possible 
explanation for this result may only require a postulation that, when subjected to shear, the normally consolidated clay shows a steady decline in volume and finally reaches the peak strength near $d(\Delta V / V) / d \varepsilon_{1}=0$ and that, as is evident from the correspondence between $d(\Delta V / V) / d \varepsilon_{1}$ and $d \varepsilon_{N} / d r$, the stress ratio $\left(\tau_{f} / \sigma_{N}\right)$ at that point has a fixed value. By contrast, when the overconsolidated clay is subjected to shear, it appears to reach the peak strength $\left(\tau_{f} / \sigma_{N}\right)$ when $d(\Delta V / V) / d \varepsilon_{1}$ assumes the maximum negative value (with volumetric expansion taken as negative). However, since the maximum value of $d(\Delta V / V) / d \varepsilon_{1}$ tends to increase with increasing value of the overconsolidation ratio, $\tau_{f} / \sigma_{N}$ is likewise increased to give rise to a curve which rises above the failure envelope for normal consolidation as shown in Fig. 7.

Verification of Relationship between Effective Principal Stress Ratio $\left(\sigma_{1} / \sigma_{3}\right)$ and Principal Increment Ratio $\left(d \varepsilon_{3} / d \varepsilon_{1}\right)$

The relationship between principal stress ratio $\left(\sigma_{1} / \sigma_{3}\right)$ and principal strain increment ratio $\left(d \varepsilon_{3} / d \varepsilon_{1}\right)$ can be derived by converting the $\tau / \sigma_{N} \sim d \varepsilon_{N} / d \gamma$ relationship on the mobilized plane into the relationship on the principal stress plane while assuming that the principal stresses and the principal strain increments agree in direction. In the case of triaxial compression test, the following equation is obtained (Matsuoka, 1973 ; 1974).

$$
\frac{d \varepsilon_{3}}{d \varepsilon_{1}}=\frac{1}{2} \cdot \frac{\sigma_{1} / \sigma_{3}-2 \mu \cdot \sqrt{\sigma_{1} / \sigma_{3}}+(\lambda-1)}{(1-\lambda) \cdot \sigma_{1} / \sigma_{3}-2 \mu \cdot \sqrt{\sigma_{1} / \sigma_{3}}-1}
$$

For the verification of Eq. (2), the results of the drained triaxial compression test on the Fujinomori clay under a fixed mean effective principal stress $\sigma_{m}=1.0 \mathrm{~kg} / \mathrm{cm}^{2}$ were used. The plots thus obtained are shown in Fig. 8. In this diagram, the solid line is a theoretical curve of the values calculated by using in Eq. (2) the values of $\mu=0.30$ and $\lambda=1.1$ (see Fig. 2). In this diagram, the shear strain at the point at which the plots rising from the lower righthand side begin to overlap the said theoretical curve is found to be about $0.7 \%$. Therefore, the principal portion up to the peak strength may be interpreted by Eq. (2).

To be definitely strict, the test conducted by using a fixed value of $\sigma_{m}$ is considered to be appropriate for the verification of Eq. (2). It is considered, however, that this verification may

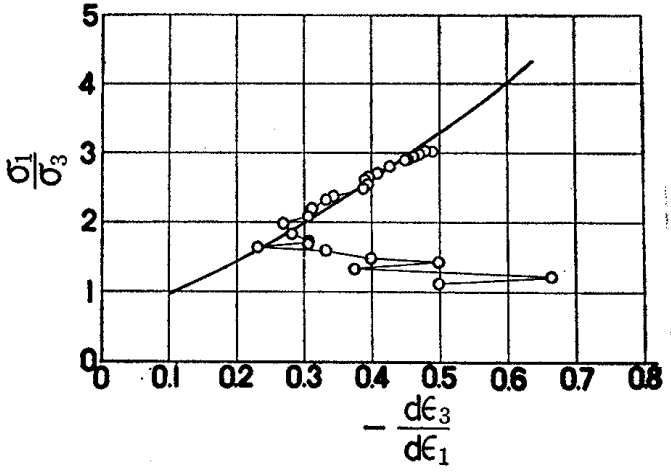

Fig. 8. Relationship between $\sigma_{1} / \sigma_{3}$ and $d \varepsilon_{3} / d \varepsilon_{1}$ in drained triaxial compression test on the Fujinomori clay approximately be accomplished by use of the data of the drained triaxial test under a fixed value of $\sigma_{3}$ which is easy to perform. In this respect, the normally consolidated Umeda clay was subjected to the drained triaxial compression test under a fixed value of $\sigma_{3}=1.0 \mathrm{~kg} / \mathrm{cm}^{2}$. Fig. 9 represents the results of this test, as rearranged in terms of the relationship between $\sigma_{1} / \sigma_{3}$ and $d \varepsilon_{3} / d \varepsilon_{1}$. In the diagram, the solid line represents a theoretical curve of the values calculated by using in Eq. (2) the values of $\lambda=0.9$ and $\mu=0.42$ (see Fig. 4). A possible reason for the relatively small value of $\lambda$ is that the Umeda clay has a high compressibility and, therefore, reflects an influence of the test condition that $\sigma_{m}$ is not constant. Fig. 10 represents the results of the drained triaxial compression test on an overconsolidated specimen of the Kaoline clay (O.C.R. $=1.5)$ under a fixed value of $\sigma_{3}=4.0 \mathrm{~kg} / \mathrm{cm}^{2}$, as rearranged in terms of the same relationship. In the diagram, the soild line represents the values calculated by using in Eq. (2) the values $\lambda=1.2$ and $\mu=0.29$ (see Fig. 5). From all these diagrams, it is noted that Eq. (2) provides a satisfactory explanation to the measured values of clays. 


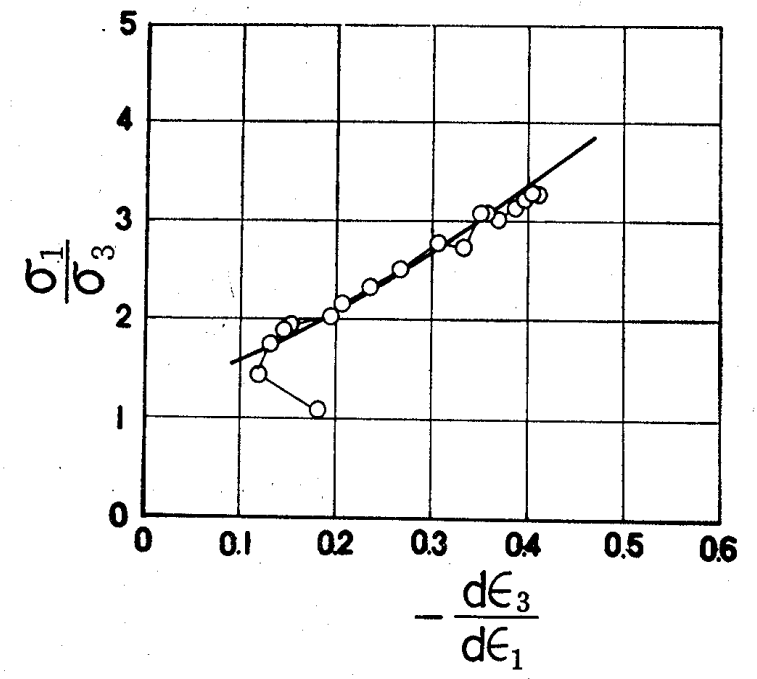

Fig. 9. Relationship between $\sigma_{1} / \sigma_{3}$ and $d \varepsilon_{3} / d \varepsilon_{1}$ in drained triaxial compression test on the Umeda clay

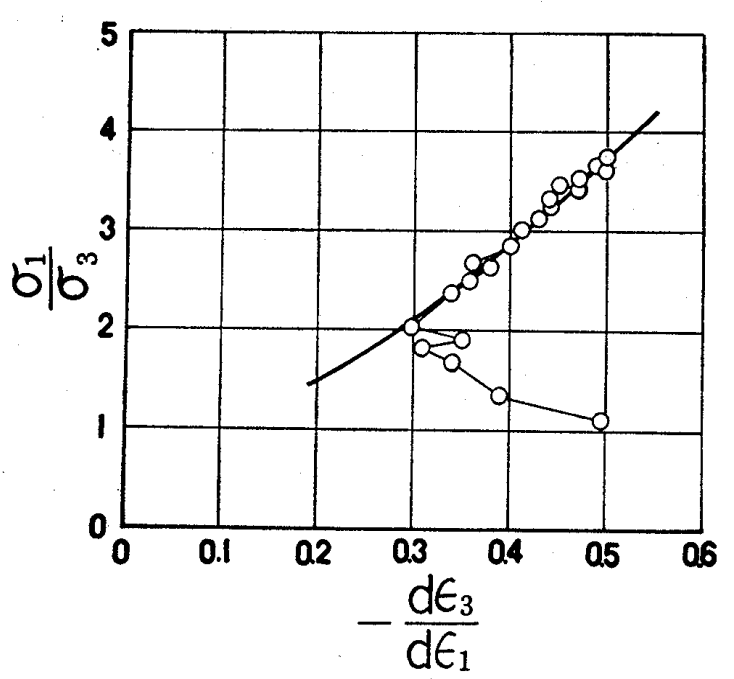

Fig. 10. Relationship between $\sigma_{1} / \sigma_{3}$ and $d \varepsilon_{3} / d \varepsilon_{1}$ in drained triaxial compression test on the Kaoline clay

Verification of Relationship among Shear-Effective Normal Stress Ratio $\left(\tau / \sigma_{N}\right)$, Shear Strain $(\gamma)$ and Normal Strain $\left(\varepsilon_{N}\right)$

In the previous papers (Matsuoka, 1972; Murayama and Matsuoka, 1973; Matsuoka, 1974), the author derived the formula of the relationship between shear-normal stress ratio $\left(\tau / \sigma_{N}\right)$ and shear strain $(\gamma)$ and that of the relationship between normal strain $\left(\varepsilon_{N}\right)$ and shear strain $(\gamma)$ on a single mobilized plane.

$$
\begin{aligned}
\frac{\tau}{\sigma_{N}} & =\left(\mu^{\prime}-\mu\right) \cdot \log _{e} \frac{\gamma}{\gamma_{0}}+\mu \\
& =2.3\left(\mu^{\prime}-\mu\right) \cdot \log _{10} \frac{\gamma}{\gamma_{0}}+\mu \\
\varepsilon_{N} & =\frac{\mu-\mu^{\prime}}{\lambda} \cdot \gamma \cdot\left\{\log _{e} \frac{\gamma}{\gamma_{0}}-1\right\} \\
& =\frac{\mu-\mu^{\prime}}{\lambda} \cdot \gamma \cdot\left\{2.3 \log _{10} \frac{\gamma}{\gamma_{0}}-1\right\}
\end{aligned}
$$

The plots of the measured data for the equations given above are shown in Fig. 11 and Fig. 12, respectively. Fig. 11 represents the data of the triaxial compression test on the Fujinomori clay $\left(\sigma_{m}=1.0 \mathrm{~kg} / \mathrm{cm}^{2}\right.$, N.C. $)$ as plotted in terms of the relationship of $\tau / \sigma_{N} \sim \gamma$ $\sim \varepsilon_{N}$ on a single mobilized plane in conjunction with the curves of the values calculated in

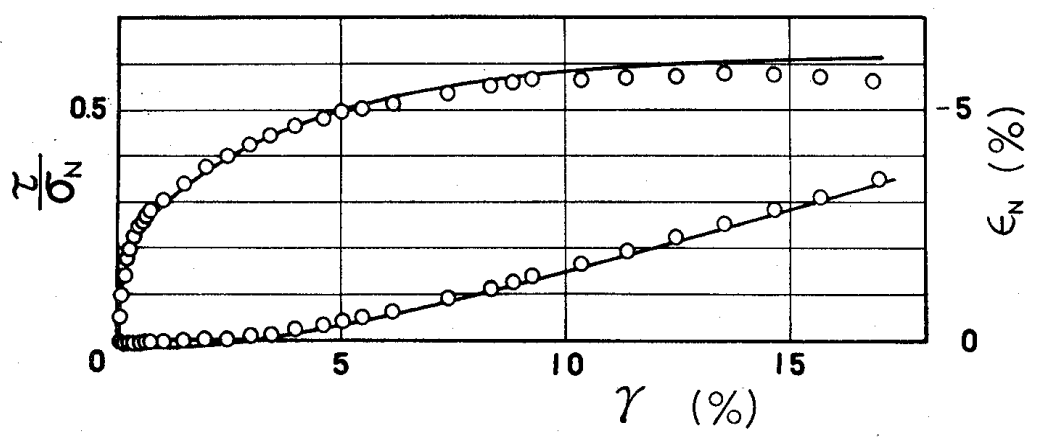

Fig. 11. Relationship among $\tau / \sigma_{N}, \gamma$ and $\varepsilon_{N}$ on one mobilized plane in drained triaxial compression test on the Fujinomori clay 


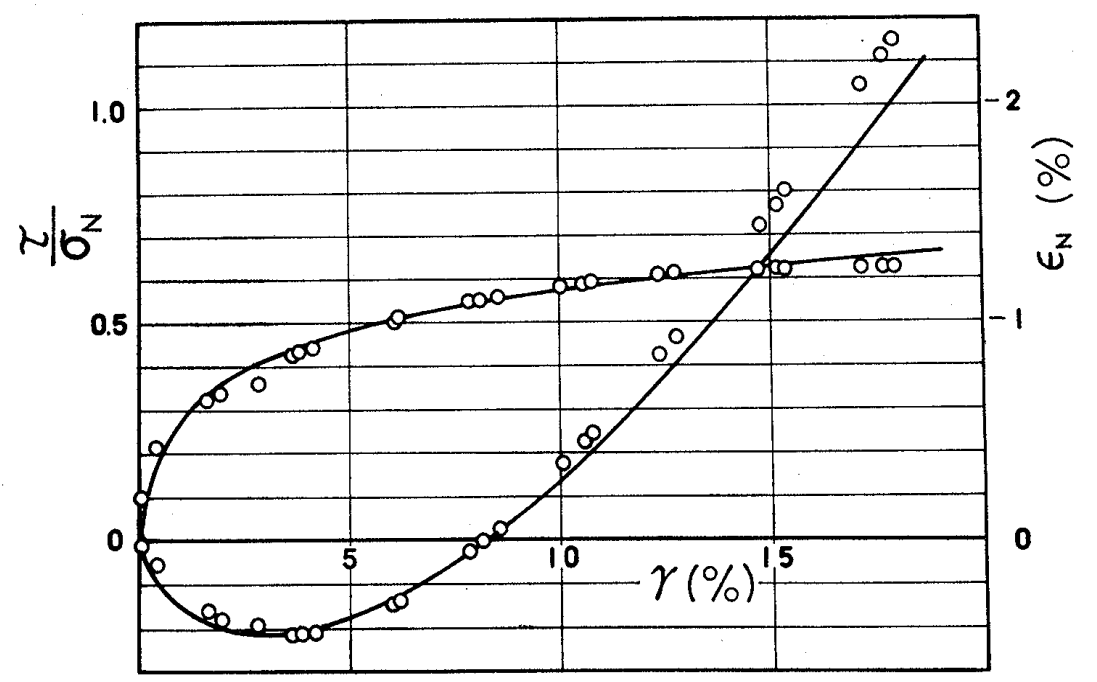

Fig. 12. Relationship among $\tau / \sigma_{N}, \gamma$ and $\varepsilon_{N}$ on one mobilized plane in drained triaxial compression test on the Umeda clay

accordance with Eqs. (3) and (4). In the related calculations, the coefficients $\lambda=1.1, \mu=$ $0.30, \mu^{\prime}=0.42$ proper to the Fujinomori clay and $\gamma_{0}=1 \%$ were used. Fig. 12 represents the data of the triaxial compression test $\left(\sigma_{3}=1.0 \mathrm{~kg} / \mathrm{cm}^{2}\right.$, N.C. $)$ on the Umeda clay as plotted in terms of the $\tau / \sigma_{N} \sim \gamma \sim \varepsilon_{N}$ relationship on a single mobilized plane in conjunction with the curves of the values calculated in accordance with Eqs. (3) and (4). In the related calculations, the coefficients $\lambda=0.9, \mu=0.42, \mu^{\prime}=0.55$ and $\gamma_{0}=3 \%$ were used. The values of coefficients just mentioned were determined by the method described in the previous papers (Matsuoka, 1973 ; 1974). It is observed from these diagrams that the curves of calculated values are in satisfactory agreement with the measured data also in the case of clays.

Verification of $\tau / \mu \cdot \sigma_{N}$ vs. $\gamma / \gamma_{0}$ Relationship

The following equation is obtained by dividing both sides of Eq. (3) by $\mu$.

$$
\begin{aligned}
\frac{\tau}{\mu \cdot \sigma_{N}} & =\left(\frac{\mu^{\prime}}{\mu}-1\right) \cdot \log _{e} \frac{\gamma}{\gamma_{0}}+1 \\
& =2.3\left(\frac{\mu^{\prime}}{\mu}-1\right) \cdot \log _{10} \frac{\gamma}{\gamma_{0}}+1
\end{aligned}
$$

The equation given above may well be considered to be what is obtained by normalizing $\tau$ and $\gamma$ respectively with $\mu \cdot \sigma_{N}\left(\equiv \tau_{0}\right)$ and $\gamma_{0}$. Further, this relationship implies that the ratios $\tau / \mu \cdot \sigma_{N}$ and $\gamma / \gamma_{0}$ give rise to linear plots past the point $(1,1)$ on the semi-logarithmic paper. Fig. 13 represents the relationship of $\tau / \mu \cdot \sigma_{N} \sim \gamma / \gamma_{0}$ derived for the Fujinomori clay and this graph indicates that the data, irrespectively of the magnitude of confining stresses, describe linear plots substantially past the point $(1,1)$. The test conditions were $\sigma_{m}=1.0$ $\mathrm{kg} / \mathrm{cm}^{2}$ for normally consolidated clay $\left(\bigcirc\right.$ marks), $\sigma_{3}=4.0 \mathrm{~kg} / \mathrm{cm}^{2}$ for normally consolidated clay ( $\left(\mathrm{marks}\right.$ ) and $\sigma_{m}=1.0 \mathrm{~kg} / \mathrm{cm}^{2}$ and an overconsolidation ratio 1.5 for overconsolidated clay (- marks), respectively. Fig. 14 represents the data obtained of the Umeda clay. Again, the data appear to describe linear plots substantially past the point $(1,1)$, irrespectively of the magnitude of confining stress. The test conditions in this case were $\sigma_{3}=1.0$ $\mathrm{kg} / \mathrm{cm}^{2}$ for normally consolidated clay $\left(O\right.$ marks) and $\sigma_{3}=4.0 \mathrm{~kg} / \mathrm{cm}^{2}$ for normally consolidated clay ( marks), respectively. Although the data available are rather few, they seem to justify a conclusion that Eq. (5) substantially holds good for clays also. 


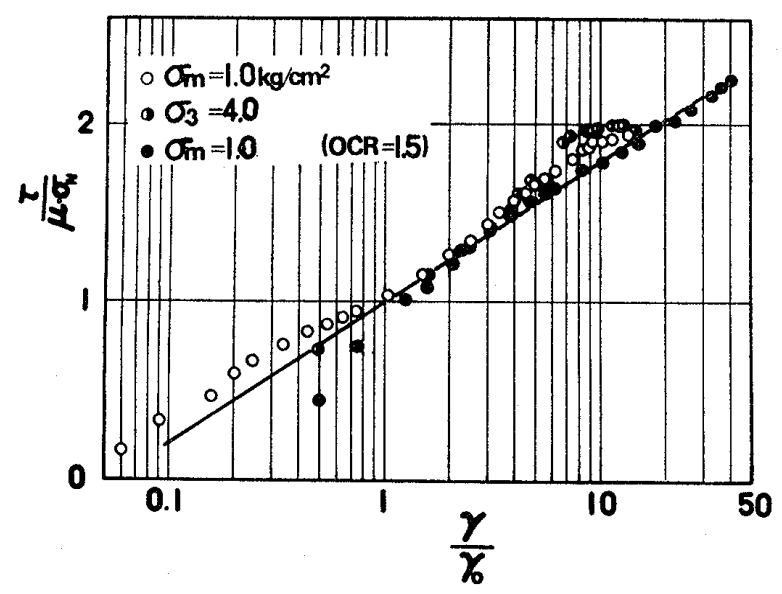

Fig. 13. Relationship between $\tau / \mu \cdot \sigma_{N}$ and $\gamma / \gamma_{0}$ on one mobilized plane measured in drained triaxial compression tests on the Fujinomori clay

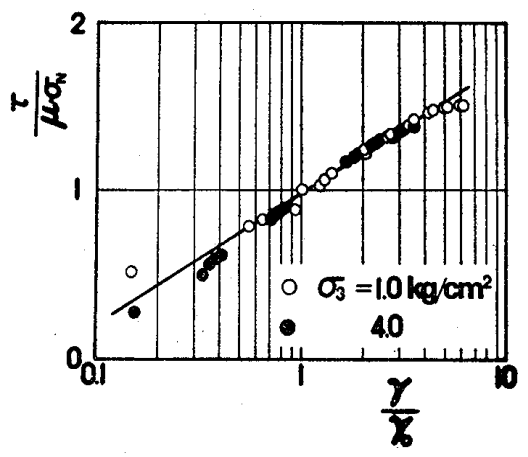

Fig. 14. Relationship between $\tau / \mu \cdot \sigma_{N}$ and $r / \gamma_{0}$ on one mobilized plane measured in drained triaxial compression tests on the Umeda clay

Verification of Relationship between Effective Principal Stress Ratio $\left(\sigma_{1} / \sigma_{3}\right)$ and Principal Strain $\left(\varepsilon_{1}\right.$ and $\left.\varepsilon_{3}\right)$ under Triaxial Compression Stress Conditions

In the previous papers (Matsuoka, $1973 ; 1974)$, the author derived the following expressions to indicate the relationship between principal stress ratio $\left(\sigma_{1} / \sigma_{3}\right)$ and principal strains $\left(\varepsilon_{1}\right.$ and $\left.\varepsilon_{3}\right)$ under triaxial compression stress conditions $\left(\sigma_{1} \geqq \sigma_{2}=\sigma_{3}\right)$ :

$$
\varepsilon_{1}=2 f\left(\frac{\sigma_{1}}{\sigma_{3}}\right), \quad \varepsilon_{2}=\varepsilon_{3}=g\left(\frac{\sigma_{1}}{\sigma_{3}}\right)
$$

wherein,

$$
\begin{aligned}
& X \equiv \sqrt{\sigma_{1} / \sigma_{3}}-\sqrt{\sigma_{3} / \sigma_{1}} \\
& f\left(\frac{\sigma_{1}}{\sigma_{3}}\right)= \frac{\gamma_{0} \cdot \exp \left(-\frac{\mu}{\mu^{\prime}-\mu}\right)}{2} \cdot \exp \left\{\frac{X}{2\left(\mu^{\prime}-\mu\right)}\right\} \\
& \cdot\left\{\frac{X^{2}}{8}+\left(\frac{1}{2}-\frac{1}{\lambda}-\frac{\mu^{\prime}-\mu}{2}\right) \cdot X+\left(\mu^{\prime}-\mu\right)^{2}-\left(\mu^{\prime}-\mu\right)+\frac{2 \mu^{\prime}}{\lambda}+1\right\} \\
& g\left(\frac{\sigma_{1}}{\sigma_{3}}\right)= \frac{\gamma_{0} \cdot \exp \left(-\frac{\mu}{\mu^{\prime}-\mu}\right)}{2} \cdot \exp \left\{\frac{X}{2\left(\mu^{\prime}-\mu\right)}\right\} \\
& \cdot\left\{-\frac{X^{2}}{8}+\left(\frac{1}{2}-\frac{1}{\lambda}+\frac{\mu^{\prime}-\mu}{2}\right) \cdot X-\left(\mu^{\prime}-\mu\right)^{2}-\left(\mu^{\prime}-\mu\right)+\frac{2 \mu^{\prime}}{\lambda}-1\right\}
\end{aligned}
$$

Therefore, the volumetric strain $(\Delta V / V)$ can be expressed as a function of the principal stress ratio $\left(\sigma_{1} / \sigma_{3}\right)$ as follows :

$$
\frac{\Delta V}{V}=\varepsilon_{1}+2 \varepsilon_{3}=2 f\left(\frac{\sigma_{1}}{\sigma_{3}}\right)+2 g\left(\frac{\sigma_{1}}{\sigma_{3}}\right)
$$

Fig. 15 represents the data of a triaxial compression test on the Fujinomori clay $\left(\sigma_{m}=1.0\right.$ $\mathrm{kg} / \mathrm{cm}^{2}$, N.C.) as plotted in terms of the $\sigma_{1} / \sigma_{3} \sim \varepsilon_{1} \sim \Delta V / V$ relationship in conjunction with the curves of the values calculated in accordance with Eqs. (6) and (7). In the related calculations, the coefficients $\lambda=1.1, \mu=0.30, \mu^{\prime}=0.42$ proper to the Fujinomori clay and $\gamma_{0}=1 \%$ were used. Fig. 16 represents the data of a triaxial compression test on the Umeda clay $\left(\sigma_{3}=1.0 \mathrm{~kg} / \mathrm{cm}^{2}\right.$, N.C. $)$ as plotted in terms of the $\sigma_{1} / \sigma_{3} \sim \varepsilon_{1} \sim \Delta V / V$ relationship in conjunction with the curves of values calculated in accordance with Eqs. (6) and (7). In 


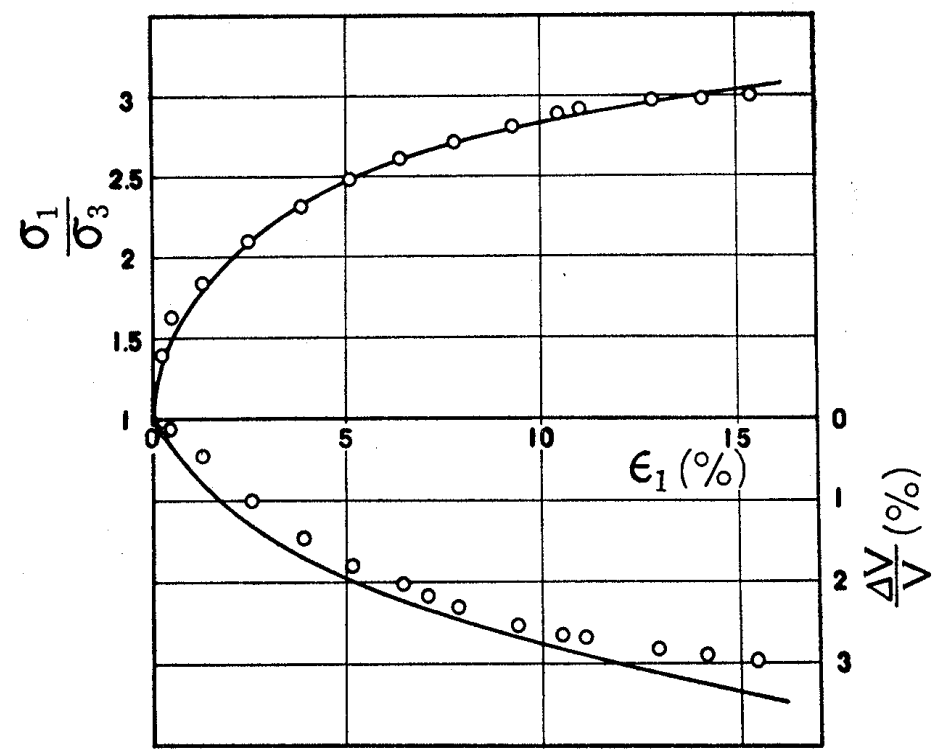

Fig. 15. Relationship among $\sigma_{1} / \sigma_{3}, \varepsilon_{1}$ and $\Delta V / V$ in drained triaxial compression test on the Fujinomori clay

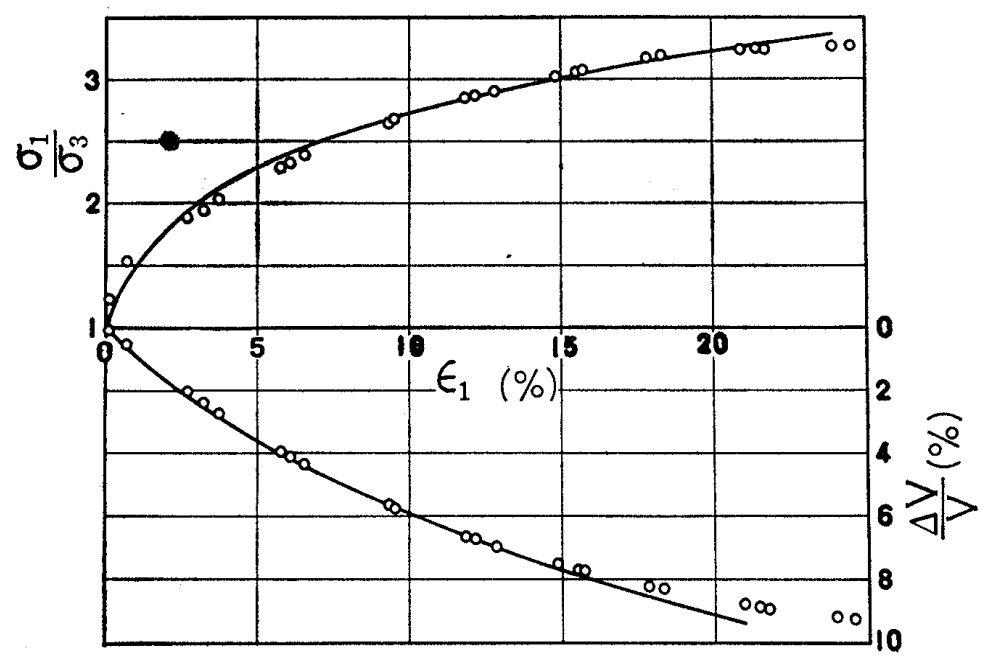

Fig. 16. Relationship among $\sigma_{1} / \sigma_{3}, \varepsilon_{1}$ and $\Delta V / V$ in drained triaxial compression test on the Umeda clay

the related calculations, the coefficients $\lambda=0.9, \mu=0.42, \mu^{\prime}=0.55$ proper to the used clay and $\gamma_{0}=3 \%$ were used. Please refer to the previous papers (Matsuoka, $1973 ; 1974$ ) for the method of determining the values of the coefficients $\left(\lambda, \mu, \mu^{\prime}\right.$ and $\left.\gamma_{0}\right)$.

\section{CONCLUSIONS}

The results which have been ascertained in this paper may be summarized as follows :

(1) It has been verified by triaxial compression tests that the linear relationship between the shear-effective normal stress ratio $\left(\tau / \sigma_{N}\right)$ and the normal-shear strain increment ratio $\left(d \varepsilon_{N} /\right.$ $d \gamma$ ) on the mobilized plane which was derived from the microscopic discussion holds good not only for sands but also for several kinds of clays. Although most test specimens used in the tests were those of normally consolidated clays, there are indications that overconsolidated clays also will yield data which will give substantially linear plots. This concept can give a 
convincing explanation to the observation that Mohr's failure envelope describes two linear (or curved) lines of two different trends, depending on whether the clay is normally consolidated or overconsolidated.

(2) The relationship between the effective principal stress ratio $\left(\sigma_{1} / \sigma_{3}\right)$ and the principal strain increment ratio $\left(d \varepsilon_{3} / d \varepsilon_{1}\right)$ has been compared with the results of triaxial compression tests on the Fujinomori clay, the Umeda clay, and the Kaoline clay. It has been verified that the calculated values show satisfactory correspondence with the measured values.

(3) The relationship among the shear-effective normal stress ratio $\left(\tau / \sigma_{N}\right)$, shear strain $(\gamma)$ and normal strain $\left(\varepsilon_{N}\right)$ on the single mobilized plane has been verified with respect to the measured data of the Fujinomori clay and the Umeda clay. Satisfactory correspondence has been confirmed as a consequence.

(4) The values measured in accordance with the $\tau / \mu \cdot \sigma_{N} \sim \log _{10}\left(\gamma / \gamma_{0}\right)$ relationship on the mobilized plane have been plotted on a semi-logarithmic section paper. Consequently, it has been learnt that under various conditions of confining stresses, the data for the Fujinomori clay and the Umeda clay produce substantially linear plots respectively.

(5) The effective principal stress ratio $\left(\sigma_{1} / \sigma_{3}\right)$-principal strains $\left(\varepsilon_{1}\right.$ and $\left.\varepsilon_{3}\right)$ relationship obtained by converting the stress-strain relationship on the mobilized plane has been verified with respect to the measured data of the Fujinomori clay and the Umeda clay. Satisfactory correspondence has been ascertained.

(6) In some aspects, sands and clays are considered to be essentially different. The difference manifests itself in the form of time effects and temperature effects, for example. It is, however, quite interesting to note that in certain aspects, both sands and clays can be handled on the basis of the same principle. This seems to suggest that the shear phenomena of sands and clays occur in a fundamentally similar mechanism. It is also very interesting to know that the data for normally consolidated clays and those for overconsolidated clays can be handled on the same rule.

\section{ACKNOWLEDGEMENTS}

The author sincerely acknowledges his indebtedness to Professor Sakuro Murayama of Kyoto University, for his continual guidance and encouragement given throughout the present study. A grateful acknowledgement is made to Professor Toru Shibata of Kyoto University, Professor Norio Yagi of Kanazawa University, Professor Daizo Karube of Kobe University and Mr. Norio Kurihara of Japan Highway Public Cooporation for their helpful advice, criticisms and encouragement.

The author also wishes to express his thanks to Messrs. Chokkan Suematsu, Ichiro Kamo, Hideo Sekiguchi, Shin-ichi Isoda, Ryosuke Kitamura and others, who were colleagues at the Professor Murayama's laboratory, for their daily discussions and support.

\section{NOTATION}

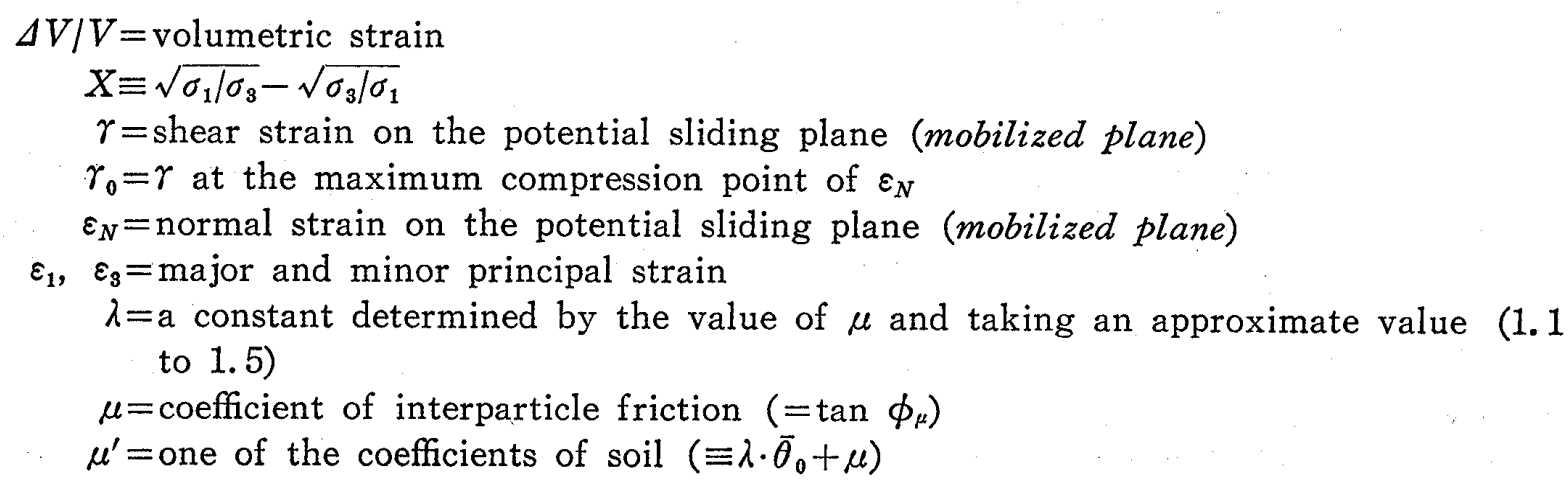


$\sigma_{N}=$ effective normal stress on the mobilized plane

$\sigma_{1}, \sigma_{3}=$ major and minor effective principal stress

$\sigma_{m}=$ mean effective principal stress

$\tau=$ shear stress on the mobilized plane

$\left(\tau / \sigma_{N}\right)=$ shear-effective normal stress ratio on the mobilized plane

$\left(d \varepsilon_{N} / d \gamma\right)=$ normal-shear strain increment ratio on the mobilized plane

\section{REFERENCES}

1) Henkel, D.J. (1956) : "The effect of overconsolidation on the behaviour of clays during shear," Géotechnique, Vol. 6, pp. 139-150.

2) Ladanyi, B., Larochelle, P. and Tanguay, L. (1965) : "Some factors controlling the predictability of stress-strain behaviour of clay," Canadian Geotech. J., Vol. 2, No. 2, pp.60-89.

3) Matsuo, S. and Kamon, M. (1973) : "Microscopic research on the consolidated samples of clayey soils, " Int. Sym. of Soil Structure, Gothenburg, Proc., pp.194-203.

4) Matsuoka, H. (1972) : "The stress-strain relation of soils under shearing derived from a microscopic consideration," Annuals, Disaster Prevention Research Institute, Kyoto University, No. 15B, pp. 499-511. (in Japanese).

5) Matsuoka, H. (1973) : "Stress-strain relationship of soils under three different principal stresses," Annuals, Disaster Prevention Research Institute, Kyoto University, No. 16B, pp.711-733 (in Japanese).

6) Matsuoka, H. (1974 a) : "A microscopic study on shear mechanism of granular materials," Soils and Foundations, Vol. 14, No. 1, pp. 29-43.

7) Matsuoka, H. (1974 b) : "Stress-strain relationships of sands based on the mobilized plane," Soils and Foundations, Vol. 14, No. 2, pp. 47-61.

8) Murayama, S. and Matsuoka, H. (1971): "The mechanism of shearing and its similarity for sands and clays," Annuals, Disaster Prevention Research Institute, Kyoto University, No.14B, pp. 551 -563 (in Japanese).

9) Murayama, S. and Matsuoka, H. (1973): “A microscopic study on shearing mechanism of soils," Proc., 8 th Int. Conf. SMFE, Vol. 1, Part 2, pp.293-298.

10) Penman, A.D.M. (1953) : "Shear characteristics of a saturated silt measured in triaxial compression," Géotechnique, Vol. 3, pp.312-328.

11) Pusch, R. (1970) : "Micro-structural changes in soft quick clay of failure," Canadian Geotech. J., Vol. 7, No. 1, pp.1-7.

(Received November 1, 1973) 